\title{
A Biblioterapia como ferramenta de restabelecimento emocional
}

\author{
Alexandre Oliveira de Meira Gusmão* \\ Elaine Gleice Jerônimo de Souza*
}

Artículo recibido:

26 de agosto de 2019

Artículo aceptado:

30 de marzo de 2020

Artículo de revisión

\section{Resumo}

Reflexão sobre o campo de atuação do bibliotecário com ênfase na eficácia da Biblioterapia para restabelecimento de indivíduos que sofrem de transtornos emocionais. O objetivo geral foi debater sobre questões ligadas aos transtornos emocionais, apresentando sugestões Biblioterapêuticas como alternativas complementares. O campo de atuação, tanto para o bibliotecário como para qualquer outro profissional, implica em perceber que cada profissão está vinculada a um determinado patamar de conhecimentos. A Biblioterapia como uma prática leitora utiliza textos verbais e não verbais como coadjuvantes no tratamento de pessoas acometidas por doenças físicas ou mentais. Indica-se a Biblioterapia para pessoas que enfrentam transtornos emocionais.

aomgusmao@hotmail.com lynegleice@gmail.com

INVESTIGACIÓN BIBLIOTECOLÓGICA, vol. 34, núm. 85, octubre/diciembre, 2020, México, ISSN: 2448-8321 pp. 33-59 
Palavras-chave: Biblioterapia; Bibliotecário; Transtornos Emocionais

Biblioterapia como herramienta de recuperación emocional Alexandre Oliveira de Meira Gusmão y Elaine Gleice Jerônimo de Souza

\section{Resumen}

Se reflexiona sobre el campo de acción del bibliotecario con énfasis en la efectividad de la biblioterapia para el restablecimiento de individuos que sufren trastornos emocionales. El objetivo general ha sido debatir temas relacionados con los trastornos emocionales, presentando sugerencias biblioterapéuticas como alternativas complementarias. El campo de acción, tanto para el bibliotecario como para cualquier otro profesional, implica darse cuenta de que cada profesión está vinculada a un determinado nivel de conocimientos. La biblioterapia como una práctica de lectura utiliza textos verbales y no verbales como complementos en el tratamiento de personas afectadas por enfermedades físicas o mentales. Se recomienda la biblioterapia para personas que enfrentan trastornos emocionales.

Palabras clave: Biblioterapia; Bibliotecario; Transtornos Emocionales

Bibliotherapy as an emotional recovery tool Alexandre Oliveira de Meira Gusmão and Elaine Gleice Jerônimo de Souza

\section{Abstract}

This reflection on the field of activity of librarians emphasize the effectiveness of Bibliotherapy in the reestablishment of individuals suffering from emotional disorders. The general objective is to discuss issues related to emotional disorders, while presenting Bibliotherapeutic suggestions as complementary alternatives. The field of action, both for the librarian as for any other professional, implies realizing that each profession is linked to a certain level of knowledge. Bibliotherapy as a reading practice uses verbal and nonverbal texts as adjuvants in the treatment of people affected by physical or mental illnesses. Bibliotherapy is recommended for people facing emotional disorders.

Keywords: Bibliotherapy; Librarian; EmotionalDisorders 


\section{INTRODUÇÃO}

Sentimentos como tristeza, angústia, ansiedade, medos, insegurança, sensação de vazio, dentre outros, fazem parte da rotina diária de milhares de pessoas, e tais sentimentos não são passageiros, nem tampouco irrelevantes, sendo que em alguns casos levam meses ou até mesmo anos para desaparecerem. Esses transtornos emocionais manifestam-se em qualquer idade, acomete pessoas em qualquer nível social, e mesmo que sejam mais comum em mulheres, transtornos emocionais também atingem o gênero masculino (Silva e Fachin, 2002; Costa e Melnik, 2016; Bernardino, Elliott e Rolim Neto, 2012; Mendes, 2008; Mintz et al., 2012; Jeffcoat e Hayes, 2012).

As pessoas com transtornos emocionais se isolam, tem oscilações de humor bastante frequentes, algumas passam a acreditar que a vida não tem mais sentido, quando isso acontece acabam se tornando indivíduos com grande potencial de cometerem suicídio. Os transtornos emocionais devem ser levados a sério, pois como se não bastassem todos esses problemas citados anteriormente, pessoas que sofrem com transtornos emocionais também enfrentam outra problemática, que é o preconceito. Travam uma luta contra a doença e outra contra o preconceito. Porque há intolerância por parte da sociedade em relação a esse tipo de doença e julgamentos como preguiça, frescura, falta de ter o que fazer, são recorrentes no dia a dia dessas pessoas.

Por medo de serem rotuladas, muitas pessoas preferem não buscar ajuda e apenas procuram um tratamento adequado quando o quadro clínico está extremamente avançado. No entanto, um diagnóstico tardio pode fazer com que o tratamento se torne muito mais longo, deixando sequelas para a vida toda ou tornando-se irreversível. Portanto, reconhecer que se está doente e buscar tratamento o mais breve possível é a atitude mais certa, pois assim o paciente tem chances de se recuperar com maior facilidade.

Aqui entra a função da Biblioterapia que, embora pouco conhecida e aplicada no Brasil, já há reconhecimento de sua eficácia, a qual pode ser utilizada como um tratamento alternativo e complementar de grande valor. A Biblioterapia, como dito anteriormente, se apresenta como uma alternativa de cura que se utiliza também e principalmente da leitura verbal e não verbal, e contribui de forma positiva no tratamento de pessoas com diagnóstico de transtorno emocional.

Dentro deste contexto, nas condições de Professor Universitário e de Graduada em Biblioteconomia, vivenciando na sociedade e nas famílias problemas de transtorno emocional, e percebendo na Biblioterapia uma ferramenta que pode auxiliar no combate à doença, pretendeu-se investigar a seguinte questão: De que modo a Biblioterapia pode ajudar no restabelecimento psíquico de indivíduos que sofrem de transtornos emocionais? 
Neste contexto, este artigo tem como objetivo geral discutir questões ligadas aos transtornos emocionais, apresentando sugestões Biblioterapêuticas como alternativas complementares para que indivíduos em período de restabelecimento psíquico possam usufruir desta prática e dos benefícios que a Biblioterapia pode proporcionar às pessoas que buscam um tratamento para transtornos emocionais.

Há necessidade de se apresentar à sociedade a disponibilidade do bibliotecário como profissional capaz de atuar como biblioterapeuta, interagindo com profissionais da área da saúde, na perspectiva de contribuir com o tratamento de indivíduos que sofrem de transtornos emocionais. Bem como, há necessidade de apresentar alternativas complementares ao tratamento de doenças emocionais vinculadas a adoção da Biblioterapia. O presente estudo também oferecer subsídios, aos acadêmicos do curso de Biblioteconomia, capazes de despertar o interesse profissional por esta possível área de atuação do bibliotecário.

Foi realizado um levantamento bibliográfico, mediante pesquisa nos Bancos de Dados do Portal de Periódicos CAPES, BRAPCI e DOAJ, utilizando-se as seguintes palavras chaves: biblioterapia, saúde mental e, transtornos emocionais. As publicações encontradas foram organizadas como de fundamentação e de pesquisa, posteriormente, mediante a análise dessas publicações, foi possível contextualizar como a Biblioterapia pode ajudar no restabelecimento psíquico de indivíduos que sofrem de transtornos emocionais.

\section{BREVE CONTEXTUALIZAÇÃO SOBRE TRANSTORNOS EMOCIONAIS}

Os transtornos emocionais não são uma enfermidade recente, estudos apontam que desde a antiguidade já se tinha notícias de casos de pessoas que manifestaram os sintomas dessa doença. Existem autores que afirmam que essa é uma questão que pode ser encontrada até mesmo nos diálogos das Sagradas Escrituras (Campos, Campos e Sanches, 2010).

No entanto, acreditava-se que se tratava de algo mítico ou algo que estava ligado diretamente a questões religiosas, pois se a doença se manifestasse em alguém, logo acreditavam que se tratava de um espírito tentando se manifestar através daquela pessoa. Hipócrates, médico e filósofo grego, foi um dos primeiros a verificar as questões da doença, e passou a enxergá-la não mais como algo sobrenatural, mas, como uma questão científica que precisava ser estudada naquele momento (Rezende, 2009).

Hipócrates desenvolveu a primeira classificação dos transtornos mentais, discriminando sistematicamente a mania, a melancolia e a paranoia. A teoria 
humoral de Hipócrates relacionavam quatro humores (substâncias que compõe o corpo humano) aos quatro temperamentos: sangue (sanguíneo), bile amarela (colérico), bile negra (melancólico) e linfa (linfático) (Campos, Campos e Sanches, 2010).

Para Hipócrates as doenças eram manifestações de um desequilíbrio entre esses fluidos e "explicariam a regulação das emoções e a formação do caráter dos indivíduos. Fundamentado nesse modelo, Hipócrates formulou a primeira classificação nosológica dos transtornos mentais registrada na história" (Souza e Lacerda, 2013: 17-18).

Hipócrates propôs que a aversão à comida, falta de ânimo, inquietação, irritabilidade, medo ou tristeza que perduravam por longo período eram resultantes de intoxicação do cérebro pela bílis negra e quanto maior a quantidade de bílis negra desenvolvida no corpo, mais grave seria o estado da doença mental (Souza e Lacerda, 2013).

Já no século XX, Sigmund Freud, um dos mais proeminentes estudiosos da época, promoveu o desenvolvimento do pensamento e do conhecimento humano. Além de ser conhecido como o pai da psicanálise, sua teoria do inconsciente continua sendo um dos pontos de referência mais importante da psicologia. Sigmund Freud foi o primeiro cientista a falar de traumas emocionais, conflitos mentais, tríades da personalidade e significado dos sonhos, e etapas sexuais do desenvolvimento. Foi um revolucionário no estudo da mente e da personalidade (Laender, 2005).

Laender (2005: 64-65) argumenta que, em seus estudos sobre o superego, Sigmund Freud, deparou-se com algo conhecido na época como melancolia e luto. A melancolia assemelhava-se ao processo do luto, contudo "é na diferenciação da reação à perda do objeto que ele ressalta a importância do mecanismo identificatório e das modificações produzidas no ego". Em relação a melancolia, Freud argumentava quanto ao indivíduo que: "ele sabe quem ele perdeu, mas não o que perdeu nesse alguém” (Freud, 1980: 277).

Atualmente, os termos transtorno, distúrbio e doença combinam-se aos termos mental, psíquico e psiquiátrico para descrever qualquer anormalidade, sofrimento ou comprometimento de ordem psicológica e/ou mental. Os transtornos mentais são campos de investigação interdisciplinar que envolve áreas como a psicologia, a psiquiatria e a neurologia. Os transtornos de humor e emocionais são tratados nas modernas classificações psiquiátricas e as classificações diagnósticas mais utilizadas como referências nos serviços de saúde e nas pesquisas são: Manual de Diagnóstico e Estatístico de Desordens Mentais V (quinta revisão) (DSM-V) e a Classificação Internacional de Doenças 10 (décima versão) (CID-10). 


\section{Os tipos mais frequentes de transtornos emocionais}

O transtorno emocional se caracteriza pela dificuldade social que o paciente apresenta. A maioria possui um comportamento dissociativo, agressivo e alienado. Há vários tipos de transtornos emocionais: depressão, ansiedade, síndrome do pânico, stress, fobia social, transtorno de personalidade borderline ou síndrome de borderline. Para tanto, será apresentado a seguir a descrição dos tipos que se manifestam com maior frequência.

Depressão. É uma doença que tem sua origem na confluência de fatores emocionais, mentais e físicos. Os sintomas podem ser tanto de ordem emocional quanto física, sendo que a tristeza persistente e profunda é o traço mais marcante da doença. Os pacientes precisam de acompanhamento médico constante e o tratamento pode incluir uso de medicamentos e terapia. Cherpe (2017:2) explica que:

A depressão é uma perturbação do estado do humor que atinge a esfera dos interesses, da vontade, da capacidade cognitiva e a regulação dos instintos. Não deve ser confundida com sentimentos de alguma tristeza (o "estar em baixo" ou "desmoralizado"), geralmente em resposta a acontecimentos marcantes da vida, que passam com o tempo e que, geralmente, não impedem a pessoa de ter uma vida de acordo com o que pretende e com um estilo protetor do próprio.

Ansiedade. A ansiedade é um grave transtorno emocional, pois prejudica a vida social e profissional da pessoa. Quem sofre desse transtorno está sempre angustiado com alguma coisa que nem sabe ao certo o que é. A ansiedade é um sentimento desagradável, vago, que faz o indivíduo ter sentimentos de medo, apreensão, é caracterizado por tensão ou desconforto derivado de antecipação de perigo, de algo desconhecido ou estranho (Allen, Leonard e Swedo, 1995). O tratamento pode ser feito com uso de medicamentos e terapia.

Síndrome do Pânico. Esse é um dos tipos de transtornos emocionais mais frequentes na atualidade, desencadeado por situações estressantes ou traumáticas. Trata-se de crises agudas de ansiedade em que o indivíduo tem intenso medo e angústia de que algo muito ruim irá acontecer, mesmo tendo consciência de que isso é improvável. Os episódios desse transtorno emocional acontecem de forma inesperada, tendo sintomas emocionais e físicos que podem levar o indivíduo até um desmaio. O tratamento para esse tipo de transtorno, também pode ser feito por meio de psicoterapia e medicamentos. Salum, Blaya e Manfro (2009: 87) explicam que: 
O transtorno do pânico (TP) é caracterizado pela presença de ataques de pânico recorrentes que consistem em uma sensação de medo ou mal-estar intenso acompanhada de sintomas físicos e cognitivos e que se iniciam de forma brusca, alcançando intensidade máxima em até 10 minutos. Estes ataques acarretam preocupações persistentes ou modificações importantes de comportamento em relação à possibilidade de ocorrência de novos ataques de ansiedade.

Stress. O stress está presente na vida de grande parte da população mundial. Seu crescimento é creditado ao estilo de vida moderno, em que os indivíduos são cobrados intensamente o tempo todo. $\mathrm{O}$ stress pode ser definido como uma condição que resulta quando as trocas entre as pessoas e meio ambiente no qual elas vivem, levam-nas a sentir uma discordância entre as exigências de uma determinada situação e os recursos do indivíduo, ao nível biológico, psicológico ou de sistemas sociais, causando-lhes o stress (Santos e Castro, 1998: 677).

O stress pode se manifestar de várias maneiras, incluindo sintomas emocionais como irritação, descontrole emocional, choro e extrema preocupação. Dependendo do caso, o paciente pode precisar de terapia.

Fobia social. Esse tipo de transtorno se dá quando há um desconforto extremo em situações sociais, como ir a uma festa, e isso vai muito além da dificuldade de estabelecer uma conversa com pessoas desconhecidas. Quando esse desconforto impede que o indivíduo realize alguma atividade em sua vida, se caracteriza como um transtorno emocional chamado de fobia social. Outro aspecto da fobia social tem sido relacionado ao processo de pensamentos negativos e a ruminação desses pensamentos relacionados a eventos sociais (Burato, Crippa e Loureiro, 2009).

Uma pessoa com esse distúrbio pode apresentar pânico em situações públicas e sociais, e a mesma tem uma dificuldade muito grande para ficar em ambientes fechados e com muitas pessoas, alguns pacientes quando se vê diante de uma situação social desconfortável, sentem alguns sintomas físicos como diarreia e sudorese, piorando ainda mais a sensação de desconforto. $\mathrm{O}$ indivíduo que sofre de fobia social pode passar por tratamento com medicamentos e psicoterapia.

Transtorno de personalidade borderline ou sindrome de borderline. Pessoas com transtornos de humor apresentam taxas altas de transtornos de personalidade borderline, antissocial, imitativo e dependente. A síndrome de borderline é um transtorno mental grave caracterizado por um padrão de instabilidade contínua no humor, no comportamento, autoimagem e funcionamento (Sadi, 2011). 
Existem vários tipos de transtornos que podem influenciar na vida social das pessoas, mas o borderline tem sido um dos quais é de difícil detecção, pois muitos indivíduos, mesmo sentindo os sintomas, podem confundi-los com a depressão e ansiedade.

Os sintomas mais frequentes dessa síndrome são: transtornos alimentares, transtornos de somatização, esquizofrenia, transtorno bipolar de humor, transtornos obsessivo-compulsivos, sexuais e dissociativos (Davison, 2002). O indivíduo que é diagnosticado com o transtorno borderline, deve ter acompanhamento assíduo, com o médico psiquiatra e profissionais da saúde. $\mathrm{O}$ tratamento se dá de forma medicamentosa e psicoterapia.

Contudo, o que se observa é que em todos os tipos de transtornos emocionais apresentados, a terapia faz parte do processo de tratamento, e a Biblioterapia pode ser uma ferramenta de auxílio à terapia convencional. Vale ressaltar, como dito em linhas anteriores, que a Biblioterapia deve ser vista como um complemento a outras terapias, e não apenas como única possibilidade de tratamento psicológico. A Biblioterapia serve de alternativas para o alívio das tensões, medos e angústias desenvolvidas e vivenciadas por pacientes, e o bibliotecário pode ser um agente facilitador neste tratamento.

\section{BIBLIOTERAPIA: HISTÓRICO E CONCEITOS}

Assim como os transtornos emocionais, a Biblioterapia também não é algo recente. Estudos apontam que a prática de usar a leitura como uma alternativa de cura remonta desde a época dos faraós. As primeiras experiências em Biblioterapia foram aplicadas entre os anos de 1802 a 1853 por médicos norte-americanos. Esses médicos acreditavam que a leitura de livros selecionados cuidadosamente e adaptados às necessidades dos indivíduos era uma das melhores receitas para seus pacientes hospitalizados (Pereira, 1996).

Em 1904, na Biblioteca do McLean Hospital, em Massachussets nos Estados Unidos, foi desenvolvido um programa que envolvia os aspectos psiquiátricos de leitura (Ratton, 1975). Neste mesmo ano a Biblioterapia passou a ser considerada como um ramo da Biblioteconomia, e essa área de conhecimento passou a ser usada principalmente nas bibliotecas públicas e hospitalares (Seitz, 2006). No entanto o termo Biblioterapia ainda não era utilizado.

Em 1916 Samuel McChord Crothers foi um dos primeiros a usar o termo Bibliotherapy. Em 1940 a Menninger Clinic que também é responsável por um sanatório e uma escola de psiquiatria voltou seus interesses para a Biblioterapia, estabelecendo-a como ciência (Pereira, 1996: 41). Em 1941 um dicionário especializado, intitulado Dorlands Ilustrated Medical Dictionary, 
conceituou a Biblioterapia como o emprego de livros e a leitura deles no tratamento de doenças psíquicas (Silva, 2013).

Em 1949, foi debatido cientificamente por Caroline Shrodes, a primeira doutora no assunto, o fato da leitura ser usada como recurso terapêutico, e após as comprovações de Shrodes, a Biblioterapia se consolidou (Ribeiro, 2006). Em 1961 um dicionário não especializado, o Webster Third International Dictionary, publicou uma definição e delimitou o termo como o uso de material de leitura, selecionado como um guia na solução de problemas pessoais através da leitura dirigida e como um coadjuvante terapêutico em medicina e psicologia (Seitz, 2006).

No Brasil foi apresentado na Câmara dos Deputados o Projeto de Lei no. 4.186, de 11 de julho de 2012, que trata do uso da Biblioterapia em hospitais públicos, o qual dispõe:

Art. $1^{\circ}$ Esta Lei dispõe sobre o uso da Biblioterapia nos hospitais públicos, contratados, conveniados e cadastrados do Sistema Único de Saúde-SUS.

Art. $2^{\circ}$ A Biblioterapia integra o conjunto das ações de saúde oferecidas pelo SUS.

$\$ 1^{\circ}$ Os materiais de leitura com função terapêutica só poderão ser prescritos e vendidos para os fins estabelecidos nesta Lei após autorização do Ministério da Saúde.

$\$ 2^{\circ} \mathrm{A}$ autorização de que trata o $\$ 1^{\circ}$ deverá considerar a eficácia terapêutica da obra.

$\$ 3^{\circ}$ Das obras autorizadas pelo Ministério da Saúde para Biblioterapia constará o número da autorização seguido do selo.

Art. $3^{\circ}$ Os familiares do paciente, mediante recomendação médica, também poderão receber a prática terapêutica biblioterápica nos hospitais públicos, contratados, conveniados e cadastrados no Sistema Único de Saúde.

Art. $4^{\circ}$ Fica autorizada a venda de obras biblioterápicas em farmácias, drogarias e livrarias.

Art. $5^{\circ}$ Esta Lei entra em vigor na data de sua publicação.

No entanto, de acordo com o Portal da Câmara dos deputados, em 2017 a Comissão de Seguridade Social e Família rejeitou a proposta que estabelece o uso da Biblioterapia nos hospitais públicos, contratados ou conveniados pelo Sistema Único de Saúde (SUS). 
O Projeto de Lei foi rejeitada pelo único colegiado responsável por analisar o mérito e a proposta foi arquivada. Entretanto, isso não impede o uso da Biblioterapia e nem o uso de debates para tentar entender seus conceitos e contribuições. O relator da proposta, deputado Jorge Silva (Câmara dos Deputados, 2017) argumentou que: "Não há obstáculos à utilização desse procedimento nos serviços do SUS” (Câmara dos Deputados, 2017).

Castro Santana e Altamirano Bustamante (2018) apresentaram uma revisão dos conceitos e facetas da Biblioterapia a partir de pesquisa em bases de dados internacionais contemplando documentos publicados posteriormente a 2005. A partir da revisão de literatura, as autoras argumentam que os resultados revelam que no México a Biblioterapia é executada esporadicamente e que os programas têm uma duração muito curta. Na sequência, as autoras apresentam uma amostra representativa de programas de Biblioterapia que existem no mundo, permitindo visualizar que as características de esporadicidade e de curta duração estão presentes em outros países.

Daí se percebe que a Biblioterapia tem um longo caminho a percorrer até se estabelecer como um programa de leitura selecionada que tem finalidades terapêuticas e executado por uma equipe multidisciplinar capaz de possibilitar o melhor restabelecimento emocional dos pacientes.

\section{O que é a Biblioterapia}

Muitos são os conceitos dados à palavra Biblioterapia. No entanto, os pesquisadores sempre concordaram que se trata de uma alternativa de cura que se utiliza da leitura para contribuir no restabelecimento de pessoas que passam por dificuldades físicas ou psicológicas.

São ações de leitura que tem finalidades terapêuticas, utilizando para tanto, de livros devidamente selecionados para tal prática. Para definir o que é a Biblioterapia, usaremos ideias de diversos autores.

Ouaknin (1996: 12) argumenta que a palavra Biblioterapia é formada por dois termos de origem grega, Biblio e Therapeia, 'livro' e 'terapia'. Deste modo, a Biblioterapia é a "terapia por meio de livros". A Biblioterapia é um tipo de leitura dirigida por um profissional bibliotecário, que pode não somente ser incluída em um processo de cura, mas também ajudar na prevenção de doenças que afetam não só o emocional, mas também em doenças que atingem o indivíduo fisicamente, porque quando uma pessoa ouve uma história ela se transporta para um mundo no qual os problemas, as dores e dificuldades são esquecidas por algum momento, ganhando uma paz espiritual a cada sessão. 
Bahiana (2009: 67), enxerga a prática da Biblioterapia como:

[...] um dos recursos terapêuticos através da ressignificação da leitura prazerosa de qualquer texto escolhido selecionado ou mesmo indicado que após a leitura, narrativa ou contada venham resultar numa paz de espírito tamanha amenizando as tensões psicossomáticas do sujeito cognitivo, consequentemente proporcionando leveza mental.

Portanto, uma dose de Biblioterapia diariamente pode fazer com que o paciente vá se distanciando daquilo que mais o aflige, e aos poucos adquirindo uma autonomia considerável em relação a algumas doenças, principalmente as emocionais, que dependem muito do querer de cada um.

A leitura deve despertar nos pacientes o desejo de se interagir e fazer com que as pessoas que estão carregando sentimentos como: angústia, solidão, receios ou anseios, entre outros, consigam expor essas sensações e aos poucos compreenderem e se libertarem desses males, dando lugar ao bem-estar físico e mental. Nesta perspectiva Ouaknin (1996: 25) conceitua Biblioterapia como:

[...] uma filosofia existencial e uma filosofia do livro, que sublinha que o homem é um ser dotado de uma relação com o livro. Dessa forma, essa relação com o livro -a leitura - permite ao homem compreender o texto e se compreender. O leitor, ao interpretar, passa a fazer parte do texto interpretado. A interpretação é a junção da explicação objetiva do texto e da sua compreensão subjetiva. A interpretação descobre outro mundo, o mundo do texto, com as variações imaginativas que a literatura opera sobre o real. A Biblioterapia, portanto, propõe práticas de leitura que proporcionem a interpretação dos textos.

Vale destacar que para esse tipo de leitura, os livros devem ser selecionados com muita responsabilidade, acolhendo as necessidades dos pacientes, caso contrário, a leitura pode ocasionar no indivíduo um estado ainda mais deprimente. Sob este ponto de vista, Seitz (2006: 158) argumenta que a Biblioterapia é: "[...] um programa de atividades selecionadas, envolvendo materiais de leitura planejadas, conduzidas e controladas como um tratamento, sob orientação médica, para problemas emocionais e de comportamento, devendo ser administrada por um bibliotecário treinado de acordo com as propostas e finalidades prescritas".

Cunha e Cavalcanti (2008: 55) definem o termo Biblioterapia como a "utilização de livros e outros materiais de leitura em programas de leitura direcionada e planejada para auxiliar no tratamento de problemas mentais e emocionais, bem como desajustes sociais". Oportunamente, cumpre esclarecer que a leitura terapêutica não é somente desenvolvida em bibliotecas de 
hospitais, mas também em presídios, casas de apoio, abrigos, serve tanto para adultos quanto para crianças, independentemente do gênero ou condições financeiras.

De acordo com todas as definições apresentadas, pode-se considerar que a Biblioterapia é uma prática de leitura dirigida que pode ser aplicada por um bibliotecário, psicólogo ou outro profissional qualificado para esta ação, e representa um importante instrumento no restabelecimento psíquico de indivíduos com transtornos emocionais.

Gómez Mujica (2017) apresenta o campo de atuação profissional que intervém na prática biblioterapêutica e do trabalho do bibliotecário e do psicólogo, suas relações profissionais e as competências necessárias.

Por sua vez, Pascoal e Ribeiro (2016) para auxiliarem o trabalho de escolha de livros para fins terapêuticos apresentam uma breve descrição e orientação sobre 120 títulos de livros que podem ser utilizados no contexto biblioterapêutico, juntamente com um roteiro para trabalhar com livros no contexto terapêutico.

\section{Os componentes biblioterapêuticos}

Com base nas pesquisas de Aristóteles e Freud, Caldin (2001), observou que há seis componentes Biblioterapêuticos, esses componentes são identificados por: Catarse, Humor, Identificação, Introjeção, Projeção e Introspecção.

Catarse. Trata-se de um termo filosófico com o significado de purificação pessoal, limpeza e pode ser entendida como pacificação, serenidade e alívio das emoções. É nessa perspectiva que se enfoca a leitura de textos literários como desempenhando uma função catártica. Esse componente defende a ideia de terapia por meio de textos literários, e aponta que as palavras são instrumentos essenciais no tratamento espiritual, pois as palavras têm o poder de convencer, emocionar, influenciar (Caldin, 2001).

Para tanto, para fazer esse tipo de tratamento não é necessário gostar de ler ou até mesmo ser alfabetizado. No entanto, o aplicador da Biblioterapia deve investir na sua capacidade de despertar no ouvinte o prazer da leitura, por isso a importância do bibliotecário se aprimorar em técnicas como, a catarse.

Humor. Esse componente defende que textos que trazem o humor como base constituem um exemplo de possibilidade terapêutica por meio da leitura. Nesta conjectura, para Caldin (2001: 38): "o humor é, pois, a rebelião do ego contra as circunstâncias adversas, transformando o que poderia ser objeto de dor em objeto de prazer". 
Pode-se dizer que as leituras humorísticas causam entusiasmo e prazer no receptor, fazendo com que o mesmo extravase os sentimentos de dor, pois com o humor vem o riso fácil. O som das gargalhadas é contagiante, e isso leva o receptor a se sentir mais feliz e possivelmente desencadear mudanças saudáveis no seu organismo. Pereira (2016: 21) argumenta que:

O humor é uma estratégia que ajuda a pessoa a escapar da opressão causada pele dor, impedindo de forma bastante proveitosa o fechamento sobre si mesmo, tão comum em estados depressivos. A possibilidade da leitura produzir estados de prazer, risos e outros afetos dessa natureza se conjuga com a utilização da Biblioterapia em pessoas em estado depressivo, e para tanto os textos selecionados, para o processo biblioterápico, devem ter a potencialidade de evocar essas reações.

Identificação. Caldin (2001: 38) explica que esse componente é um "fator importante na teoria freudiana do desenvolvimento da personalidade - começa cedo na nossa vida. As crianças se identificam com os pais, com pessoas que admiram e com os animais". Segundo Laplanche e Pontalis (1994: 226) a identificação é "um processo psicológico pelo qual um sujeito assimila um aspecto, uma propriedade, um atributo do outro e se transforma, total ou parcialmente, segundo o modelo desse outro".

Por isso a importância do biblioterapeuta exercer a função de líder, ser exemplo para os que estão sob seus cuidados. É ideal fazer com que a pessoa mesmo passando por transtornos emocionais aprenda a se admirar, a buscar em si a vontade de vencer seus anseios ou receios. É sempre bom ter a quem se espelhar, e o bibliotecário pode ser um espelho de boas ações que ajudam a elevar a autoestima do outro.

Introjeção. A introjeção é um componente que se constitui em um processo evidenciado por análises que o sujeito faz passar, de um modo imaginário, de 'fora' para dentro', objetos e qualidades inerentes a esses objetos (Laplanche e Pontalis, 1994: 248). Caldin (2001: 39), aponta que este componente "está estreitamente relacionado com a identificação".

Projeção. É a transferência de nossas ideias, sentimentos, intenções, expectativas e desejos a outras pessoas. Segundo Laplanche e Pontalis (1994: 374), a projeção é, "no sentido propriamente dito, operação pela qual o sujeito expulsa de si e localiza no outro - pessoa ou coisa - qualidades, sentimentos, desejos e mesmo 'objetos' que lê, desconhece, ou recusa nele". 
Introspecção. A introspeção, segundo Michaelis (1998: 699), é a "descrição da experiência pessoal em termos de elementos e atitudes" a "observação, por uma determinada pessoa, de seus próprios processos mentais". Dessa forma, a leitura, ao favorecer a introspecção, leva o indivíduo a refletir sobre os seus sentimentos, e essa reflexão é terapêutica, pois sempre desponta a possibilidade de mudança no modo pelo o qual o indivíduo se comporta.

\section{Os tipos de Biblioterapia}

Existem três tipos de Biblioterapia, elas são classificadas em: Institucional, Clínica e Desenvolvimental. Independentemente do tipo de Biblioterapia, antes de aplica-la é essencial um diagnóstico bem estruturado que norteie o bibliotecário para a aplicabilidade do tratamento. Ponderam-se nos parágrafos a seguir as características e as ações que cada tipo pode oferecer (Pereira, 2016:25-27).

a) Biblioterapia institucional: é uma modalidade de Biblioterapia que se refere primeiramente ao ensino de métodos e técnicas que auxiliam na aprendizagem do receptor, e se refere a literatura. Este tipo de ação terapêutica é exercido por um bibliotecário, juntamente com um médico ou uma equipe médica. $\mathrm{O}$ objetivo principal é informativo e recreativo. Embora este tipo de Biblioterapia não prevaleça mais nos dias atuais, ainda existem alguns programas semelhantes. A Biblioterapia institucional também inclui o uso da comunicação dos médicos com pacientes individuais, em prática privada (Pereira, 2016: 25).

b) Biblioterapia clínica: este tipo de Biblioterapia se refere ao uso, numa primeira fase, da literatura imaginativa, com grupo de pacientes que passam por problemas emocionais ou comportamentais. Esses pacientes podem ou não participar do programa voluntariamente, eles podem ser liderados por um médico ou por um bibliotecário, mas geralmente, este tipo de Biblioterapia é realizado pelos dois profissionais, um consultando o outro. $\mathrm{O}$ ambiente pode ser um instituto ou uma comunidade, objetivando uma possível mudança no comportamento (Pereira, 2016: 26).

c) Biblioterapia desenvolvimental: refere-se ao método que utiliza a literatura de maneira imaginativa e didática para o tratamento das pessoas que não apresentam nenhum distúrbio ou alteração no comportamento. É realizada em grupo e com a liderança do profissional bibliotecário, ou outro profissional. Sua meta é ajudar as pessoas a 
realizarem tarefas comuns e suportarem problemas diários (Pereira, 2016: 27).

\section{Os benefícios da Biblioterapia}

Inicialmente, vale registrar, que inexiste qualquer contraindicação no uso da Biblioterapia, o que se pede aos profissionais da área é que tenham um cuidado minucioso ao escolher o livro, que deve ser adequado a cada indivíduo e seu problema, caso contrário, feito um diagnóstico errado e prescrito um tipo de leitura imprópria para o momento, pode-se alterar as emoções, elevar o nível de sentimentos ruins e prejudicar ainda mais o portador de distúrbio emocional.

Além disso, verifica-se na literatura que os benefícios são muitos, e que esse processo tão natural que independe de drogas para alívio da dor, permite ao receptor a oportunidade de encarar as perspectivas e buscar outras formas de pensar e sentir. Lista-se a seguir alguns dos vários benefícios atribuídos e comprovados por pesquisadores da área da Biblioteconomia sobre a função biblioterapêutica (Valência e Magalhães, 2015).

A leitura ajuda o indivíduo a compreender a si, distinguir o que é ou não característico seu, e o que foi trazendo para dentro da sua vida no decorrer da sua história. Portanto, a leitura quando desperta no paciente a vontade do autoconhecimento, ajuda-o a descobrir qualidades e capacidades que já possui, mas que ainda não havia transportado para sua realidade.

$\mathrm{O}$ autoconhecimento vai aos poucos trazendo a pessoa para a realidade, evidenciando a ela a maneira como se comportar e como reagir em situações que possam causar abalos emocionais, e contribuindo para que tais ocorrências, sejam elas em situações de extrema alegria ou tristeza, não lhe cause danos psicológicos.

Valência e Magalhães (2015: 8) explicam que a Biblioterapia “auxiliará o autoconhecimento pela reflexão, reforçando padrões sociais desejáveis, facilitando o desenvolvimento emocional pelas experiências de outra pessoa e ajudando na mudança do comportamento".

A Biblioterapia representa uma melhora na autoestima do paciente, pois a aplicação da mesma como coadjuvante no tratamento de transtornos emocionais contribui de forma positiva, uma vez que a leitura pode fazer com que o receptor se inspire em um personagem alegre, ousado com uma autoestima elevada e aplique essa atitude do personagem no seu cotidiano.

Esse tipo de leitura orientada ajuda o paciente no processo de socialização, pois conforme mencionado no tópico "Os tipos mais frequentes de transtornos emocionais", alguns tipos de transtornos emocionais como a fobia social, impede que o paciente se socialize, já que nesse caso é comum que 
o mesmo se sinta julgado o tempo todo, e se retraia, apesar de que tais julgamentos são, em grande parte, criações de sua mente.

A Biblioterapia direcionará o paciente a ter uma visão realista dos acontecimentos e o faz compreender que julgamentos são comuns quando se vive em sociedade, mas que se deve abstrair aquilo que não diz respeito a ele. Só assim conseguirá pacificar, um pouco, os sentimentos degradantes que causam tantas sensações negativas. Assim, Caldin (2001: 32) explica que:

A função terapêutica da leitura admite a possibilidade de a literatura proporcionar a pacificação das emoções [...], o ato de excitamento das emoções de piedade e medo proporciona alívio prazeroso. A leitura do texto literário, portanto, opera no leitor e no ouvinte o efeito de placidez, e a literatura possui a virtude de ser curativa e sedativa.

Outra contribuição importante da Biblioterapia é a de poder compartilhar as experiências junto a um grupo de pacientes que também utilizam a leitura orientada, pois este mecanismo permite a estes compreender que não estão sozinhos, sem contar que a troca de informações pode oferecer soluções mútuas para os participantes do grupo de leitura.

Com base nos estudos de Caldin (2001), pode-se dizer que a Biblioterapia proporciona as seguintes contribuições:

a) Favorece a identificação dos pacientes com os personagens da história.

b) Ajuda o paciente entender suas limitações, reações, conflitos e frustrações.

c) Facilita a comunicação do paciente com a equipe médica.

d) Aumenta a autoestima, diminui a timidez e estimula a criatividade do paciente.

e) Alivia as tensões do dia a dia.

f) Facilita a socialização por causa das participações em grupo.

g) Cria um universo independente na vida cotidiana e ajuda o paciente a se adaptar a vida hospitalar.

\section{A FUNÇÃO DO BIBLIOTECÁRIO}

A Biblioterapia é uma opção de tratamento, e pode ser uma área na qual o bibliotecário poderá atuar (Pinto, 2005). Para tanto, vale ressaltar que para exercer essa profissão o bibliotecário precisa ser especializado e seguir normas para a aplicabilidade do tratamento, até mesmo porque não se faz leituras sem uma seleção cautelosa dos livros, pois os pacientes precisam antes, 
serem diagnosticados e a partir desse conhecimento prévio sobre eles, o profissional tem condições de selecionar livros que tragam alívio a indivíduos que apresentam transtornos emocionais, pois estes tem o poder de ajudar as pessoas a superar as dificuldades, e o bibliotecário pode ser um agente facilitador (Leite, 2009). A respeito da leitura, Ouaknin (1996: 18) pontua que:

[...] a leitura oferece ao leitor, por identificação e "cooperação textual", por apropriação e projeção, a possibilidade de descobrir uma segurança material e econômica, uma segurança emocional, uma alternativa à realidade, uma catarse dos conflitos e da agressividade, uma segurança espiritual, um sentimento de pertencimento, a abertura a outras culturas, sentimentos de amor, o engajamento na ação, valores individuais e pessoais, a superação das dificuldades [...].

O bibliotecário precisa estar ciente do conteúdo do livro que está prescrevendo, por isso será necessário que o mesmo desenvolva um plano para seguir junto ao paciente, principalmente nas primeiras etapas do tratamento. Assim o bibliotecário terá condições de se preparar para estar apto a responder as perguntas e sanar as dúvidas que o paciente possa ter. A biblioterapia não se aplica com qualquer tipo de leitura, qualquer livro ou assunto, é preciso cautela e muito discernimento na hora da escolha sobre a leitura que se pretende executar. Os biblioterapeutas na fase do diagnóstico elaboram um plano de leitura orientada, determinando o que deve ser lido, e como deve ser lido. Sob esta compreensão, Alves (1982: 56) pondera que:

[...] cabe sempre ao bibliotecário a escolha do material que deve ser cercado de muita atenção e cuidado, de maneira a corresponder aos gostos, nível intelectual, tendências e idade do grupo. A seleção dos documentos deve, também, ser feita de maneira a levar otimismo e alegria às sessões, evitando, sempre inibir ou deprimir o paciente. O livro deve ajudá-lo na solução de seus problemas, sem aumentar-lhe o sentimento de culpa, mas também sem inocenta-lo, procurando sempre um exemplo imitável.

Dentro deste contexto percebe-se a importância do profissional capacitado para tal função, uma vez que a leitura não pode se tornar uma agravante e sim uma solução. Logo, o bibliotecário deve ser capaz de se atentar a um tipo de conteúdo eficaz, capaz de ajudar esses pacientes a aceitar a realidade, disseminando leituras que consigam transformar esses sintomas que muitas vezes parecem ser impossíveis de suportar, em manifestações menos angustiantes. Lucas, Caldin e Silva (2006: 399) destacam a importância do bibliotecário como biblioterapeuta, argumentando que: 
O bibliotecário não deve assumir o papel de guardião dos livros como acontecia há alguns anos. A realidade dos campos de atuação desse profissional está ampliando-se cada vez mais e assumir esse momento é essencial para o fortalecimento e reconhecimento da profissão. De maneira alguma diminui-se a importância da técnica da profissão do bibliotecário, afinal é a sua essência. Porém, exercer o papel social é, de certa maneira, o ápice, considerando a realidade atual do país, que tem sede de cidadãos leitores e de agentes fomentadores da leitura. A Biblioterapia é um exemplo desse novo momento da profissão. Há muito tempo ela vem sendo exercida por profissionais da saúde, psicologia, terapeutas. Embora ainda hoje haja a predominância desses profissionais na aplicação da Biblioterapia, existem casos em que esta vem sendo aplicada por bibliotecários e apresentando ótimos resultados.

O bibliotecário deve procurar discutir detalhes relevantes como preocupações e dificuldades que o paciente possa ter tido com o livro, e se acaso houver esses problemas, é necessário que o bibliotecário recorra ao médico para que ambos, trabalhando em conjunto possam tomar as medidas cabíveis para sanar as dificuldades, evitando, assim que o paciente desista da leitura do livro.

No que tange a discriminação das práticas biblioterapêuticas pode-se entender que se houver desconhecimento por parte dos profissionais da área da saúde sobre os tratamentos que a Biblioterapia oferece ou até mesmo sobre o que é a Biblioterapia, caberá ao bibliotecário divulgar os benefícios e mostrar como os projetos de leituras podem se tornar um aliado na prevenção e combate aos distúrbios psicológicos.

Barreto (1994: 3) argumenta que: "a informação é qualificada como um instrumento modificador da consciência e da sociedade como um todo e tem o poder de modificar a consciência do indivíduo e da sociedade". Por isso a importância da divulgação da Biblioterapia como parte das ações do bibliotecário.

Levar informação aos que desconhecem esta prática e motivar a sociedade a buscar este tipo de tratamento, é um trabalho tão importante quanto a Biblioterapia em si. Por mais que a Biblioterapia pareça um campo ainda timidamente explorado, com boas informações sobre o assunto os pacientes poderão sentir desejo de optar por essa alternativa, e isso poderá ampliar-se e quando menos se esperar o bibliotecário com seus projetos de leituras dirigidas terá destaque e valor merecido pelo trabalho eficaz.

Diante das limitações que pacientes com transtornos emocionais apresentam cabe ao bibliotecário buscar informações pontuais a respeito da leitura medicamentosa para que ele possa prescrever materiais que de fato colaboram na solução ou redução do problema. 
Caldin (2001: 36) pontua que: "a leitura possibilita o homem compreender o texto e se compreender", e que os indivíduos com problemas emocionais precisam se autocompreender, aceitar a realidade e buscar ajuda profissional para reverter essa condição.

Ainda possuindo algumas limitações como à falta de bibliotecários que possam coordenar um programa biblioterapêutico; pouco conhecimento sobre o leitor; a ausência de um estudo que relacione os problemas de saúde e os tipos de leituras mais adequadas; e a falta de bibliotecas (Seitz, 2006), a Biblioterapia se faz importante pois estimula a independência do paciente, e colabora com o nível de resistência que indivíduos com transtornos emocionais apresentam.

$\mathrm{Na}$ perspectiva de capacitar os discentes a utilizarem a leitura como atividade biblioterapêutica Caldin (2005) relata as experiências dos projetos de extensão direcionados ao desenvolvimento de atividades de leitura com possibilidades terapêuticas executados por discentes matriculados no segundo semestre de 2004 na disciplina de Biblioterapia do curso de Biblioteconomia da Universidade Federal de Santa Catarina. Foram executados oito projetos, sendo cinco direcionados a crianças, um a jovens e adultos e dois a idosos. A autora argumenta que a "articulação do literário com a função terapêutica da leitura promoveu a catarse, o humor, a identificação, a introjeção, a projeção e a introspecção dos agentes envolvidos, mostrando-se a Biblioterapia um instrumento eficaz no combate às tensões da vida diária” (Caldin, 2005: 13).

Ao oferecer um livro, o bibliotecário não deve deixar o leitor sozinho, a Biblioterapia funciona como uma atividade recreativa em que interagir com outras pessoas é fundamental. Oferecer o livro faz parte das atividades do bibliotecário, mas se envolver e participar das fantasias que o receptor vai criando no decorrer da leitura é fundamental.

A seguir apresentamos uma lista de investigações prévias, a qual pode ajudar a identificar as descobertas que são comuns nos diferentes estudos sobre Biblioterapia, assim como comparar e contrastar os resultados destes estudos.

a) Remor, 1997. Objetivo: Melhorar o estado anímico da paciente, e desaparecimento da sintomatologia depressiva. Amostra: Caso clínico com a avaliação e o tratamento, a partir do modelo psicoterapêutico cognitivo, de uma paciente portadora de HIV, com 30 anos, que apresentava sintomas de depressão como consequência do diagnóstico de soropositividade. Metodologia: Relato de experiência. A intervenção psicológica consistiu em nove sessões, de periodicidade semanal, com duração de 1 h e 15 min, num período de quatro meses e meio e uma sessão de seguimento após as férias (60 dias) da 
paciente. Também foram utilizados recursos de biblioterapia, tanto durante o período de tratamento, como durante o período de férias. Transtorno: Depressão, Stress. Intervenção em Biblioterapia: A intervenção consistiu em entregar bibliografia a paciente, que trata os temas que havia solicitado, temas de interesse ou deficitários para a paciente. Resultados: Melhora do estado anímico da paciente, com o desaparecimento da sintomatologia depressiva. A biblioterapia, como tarefas para casa, auxiliou no processo terapêutico, inclusive proporcionando que as intervenções sejam mais curtas e eficazes.

b) Caldin, 2002. Objetivo: Humanizar o processo de tratamento das crianças realizando a leitura de histórias com propósitos terapêuticos. Amostra: Crianças internadas e em tratamento no Hospital Universitário da UFSC. Metodologia: Relato de experiência. Ações de Biblioterapia desenvolvidas em agosto de 2001 e de março a maio de 2002. Transtorno: Depressão, Stress. Intervenção em Biblioterapia: Procedeu-se à leitura em grupo e à leitura individual. Utilizou-se alguns recursos lúdicos como música, dramatização, "contação" e gravuras. Resultados: Os resultados obtidos confirmaram que a biblioterapia conduz à pacificação das emoções pela satisfação das necessidades estéticas.

c) Silva e Fachin, 2002. Objetivo: Descrever a atividade de leitura para alunos do Instituto de Educação Especial "Prof. Manoel Boaventura Feijó" - Associação de Pais e Amigos dos Excepcionais - APAE de Florianópolis. Amostra: 32 estudantes. Metodologia: Pesquisa experimental com atividades de leitura para 32 estudantes portadoras de necessidades especiais e com idades entre 5 e 59 anos. Transtorno: Paralisia cerebral, síndrome de Down, deficiência mental, esquizofrenia. Intervenção em Biblioterapia: Leitura de livros, leitura de textos históricos, fantoche e música. Resultados: Desenvolvimento crítico e intelecto, bem como estimulação do imaginário.

d) Seitz, 2005. Objetivo: Verificar o nível de aceitação da leitura como atividade de lazer pelos pacientes internados nas Clínicas Médicas do HU/UFSC. Amostra: 47 internos nas Clínicas Médicas do HU/ UFSC. Metodologia: Pequisa experimental. Prática biblioterapêutica desenvolvida nas clinicas médica, onde internam pacientes com diagnósticos nas seguintes especialidades: oncologia, reumatologia, pneumologia, gastroenterologia, nefrologia, hematologia, cardiologia, neurologia e endocrinologia. Encontros com os pacientes realizados duas vezes por semana, nas terças e quintas-feiras. Transtorno: Ansiedade, Depressão, Stress. Intervenção em Biblioterapia: Oferta 
de livros, revistas e jornais para leitura. Resultados: A prática biblioterapêutica com pacientes internados em clínica médica demonstrou ser útil no processo de hospitalização, como fonte de lazer e de informação, na interação biblioterapeuta / paciente / enfermagem e, no processo de sociabilização, além, de proporcionar momentos de descontração e alegria aos pacientes, contribuindo para o bem estar mental dos mesmos.

e) Lucas, Caldin e Silva, 2006. Objetivo: Identificar as contribuições da aplicação da Biblioterapia nas crianças em idade pré-escolar matriculadas em período integral no Centro de Educação Nossa Senhora da Boa Viagem. Amostra: 22 crianças matriculadas na pré-escola em período integral no nível maternal III (4 anos de idade). Metodologia: Pesquisa experimental. A coleta de dados foi obtida por meio da observação do comportamento das crianças. Transtorno: Ansiedade. Intervenção em Biblioterapia: Atividades de contação de história. Resultados: As crianças pareciam muito felizes e gratas pela atenção, carinho e dedicação recebida, ratificando que atividades como as desenvolvidas em todo o trabalho podem auxiliar no amadurecimento afetivo, emocional e físico das crianças envolvidas.

f) Dohnt e Tiggemann, 2008. Objetivo: Avaliar um livro de ilustrações infantis chamado de Shapesville e concebido para promover uma imagem corporal positiva entre as crianças pequenas. Amostra: 84 meninas (com idade entre 5 a 9 anos). Metodologia: Avaliações de imagem corporal, estereotipagem com base no peso e internalização da mídia, bem como do conhecimento de tópicos não relacionados à aparência, antes e depois da intervenção, e no acompanhamento de seis semanas. Transtorno: Transtornos alimentares. Insatisfação corporal. Intervenção em Biblioterapia: Leitura do livro Shapesville ou um livro de controle. Resultados: Em comparação ao livro de controle, a satisfação das meninas com a aparência aumentou após a leitura de Shapesville. Além disso, a estereotipagem com base no peso e a internalização de ideais midiáticos diminuíram. Finalmente, a leitura de Shapesville também aumentou a base de conhecimento das meninas sobre tópicos não relacionados à aparência.

g) Seitz, 2008. Objetivo: Verificar até que ponto a prática biblioterapêutica, as atividades culturais e de entretenimento contribuem no processo de humanização da assistência hospitalar dos pacientes internados nas UIC I e II do HU/UFSC na percepção dos pacientes, acompanhantes, funcionários da enfermagem e assistentes sociais da referida unidade de internação. Amostra: Foram entrevistados 
16 pacientes, 11 acompanhantes e 13 funcionários da enfermagem e assistentes sociais. Metodologia: Pesquisa experimental. A prática biblioterapêutica acontece todas as $2^{a}$ e $5^{a}$ feiras e as atividades de lazer nas $4^{a}$ feiras, os dados foram coletados nas $6^{a}$ feira visando, assim, foi possível coletar dados dos pacientes que participaram de uma ou mais atividade. Transtorno: Ansiedade, Depressão, Stress. Intervenção em Biblioterapia: Oferta de livros, revistas e jornais para leitura, participação das atividades do grupo Reaja e a dança. Resultados: Resultados demonstram que as atividades contribuem muito na Humanização da Assistência Hospitalar dos pacientes internados na UIC/HU/UFSC.

h) Bahiana, 2009. Objetivo: Identificar, refletir e trazer à discussão, as práticas e projeções pedagógicas e familiares relacionadas ao uso da biblioterapia que induzem a comunidade universitária a futuras interações e à prática da leitura. Amostra: Estudantes do oitavo semestre do curso de Pedagogia da Faculdade de Ciências Educacionais - FACE. Metodologia: Pesquisa descritiva e coleta de dados por questionário. Transtorno: Stress. Intervenção em Biblioterapia: Indicação de livros de autoajuda, livros e textos humorísticos. Resultados: A técnica da biblioterapia relaxa e ameniza a tensão mental.

i) Ceribelli et al., 2009. Objetivo: Descobrir em que medida a estratégia de leitura de histórias proposta pelo Projeto Biblioteca Viva em hospitais pode ser um recurso de comunicação para uso em crianças hospitalizadas. Amostra: Mediadores e crianças maiores de sete anos. Metodologia: Pesquisa experimental. Para coleta de dados utilizou entrevista semiestruturada com mediadores e crianças maiores de sete anos. Transtorno: Depressão, Stress. Intervenção em Biblioterapia: Leitura de histórias infanto-juvenis, por intermédio de profissionais e voluntários capacitados para tal função. Observação de sessões de mediação de leitura. Resultados: A mediação de leitura facilita os diálogos e o relacionamento, amplia o processo de diagnóstico e terapêutico e valoriza o processo de desenvolvimento de crianças, familiares e equipe de saúde.

j) Bernardino, Elliott e Rolim Neto, 2012. Objetivo: Humanizar o tratamento das crianças hospitalizadas, realizando a leitura de histórias com propósitos terapêuticos. Amostra: Crianças com câncer em tratamento no Hospital Municipal Infantil Maria Amélia Bezerra de Menezes, localizado na Cidade de Juazeiro do Norte-CE. Metodologia: Relato de experiência do projeto de extensão "Biblioterapia com crianças com câncer, a leitura como atividade lúdica”. A frequência 
ao hospital em duas vezes por semana, durante o ano de 2010. Transtorno: Stress, Depressão. Intervenção em Biblioterapia: Leitura em grupo e individual, a contação de histórias, dramatização e oficinas de desenho. Resultados: A biblioterapia conduz à pacificação das emoções, a desfocalização do problema de saúde enfrentado, reforçado pelas qualidades estéticas oferecidas pela literatura. A leitura apazigua as emoções resultantes da doença e conduzem a estados de espíritos suscetíveis ao tratamento.

k) Oliveira et al., 2011. Objetivo: Avaliar o impacto da leitura e contação de histórias mediadas para a recuperação das pessoas hospitalizadas. Amostra: Internos nas clínicas médica, ortopédica e cirúrgica do Hospital Regional Irmã Elza Giovanella, em Rondonópolis - MT. Metodologia: Relato de experiência. Utilização de técnicas de leitura e de contação de histórias com todos os participantes da pesquisa. A coleta de dados por questionários e entrevista. Foram entrevistados 20 pacientes, sendo 12 do sexo masculino e oito do sexo feminino. Transtorno: Depressão, Stress. Intervenção em Biblioterapia: Leitura e contação de histórias. Resultados: Constatam que as atividades de leitura e contação de histórias proporcionam momentos alegres e descontraídos, transmitindo, conforto e bem-estar às pessoas que se encontram hospitalizadas.

\section{CONSIDERAÇÕES FINAIS}

Diante do estudo realizado através das bibliografias consultadas, observou-se que os transtornos emocionais têm uma característica de isolamento social, angústias, medos e tristezas. Desse modo, demonstrando que a Biblioterapia é um tipo de tratamento alternativo eficiente, o passo seguinte foi discutir sua aplicação, a qual ainda é pouca utilizada no Brasil, e a função social do bibliotecário, que é um agente facilitador dos conhecimentos Biblioterapêuticos.

A leitura usada como uma ferramenta no restabelecimento de pacientes com transtornos emocionais coloca o bibliotecário como um aliado que intermédia e sustenta essa ação. O bibliotecário não trabalha sozinho, mas em conjunto com outros profissionais, e se destacam por terem um perfil social para atender as necessidades humanitárias do paciente.

Muitas vezes os pacientes precisam de um olhar menos clínico e mais humano que o tire da vida monótona de um hospital e o transporte para um lugar no qual as dificuldades ou as dores são adormecidas, mesmo que por alguns minutos. E assim, uma dose diária de Biblioterapia pode ir aos 
poucos, recuperando o doente e o trazendo de volta para uma vida saudável e equilibrada.

Refletindo sobre o assunto tratado, conclui-se que o bibliotecário pode contribuir com os profissionais da área da saúde, conquanto ainda hajam poucos profissionais trabalhando na área, e que em alguns lugares são os próprios profissionais da saúde que desenvolvem esse tipo de ação.

Assim, muito se tem a trilhar até que a Biblioteconomia, mais especificamente, com a Biblioterapia ocupe seu lugar de direito, o qual até o presente momento se encontra vago e que os bibliotecários também exerçam suas funções como biblioterapeutas.

\section{REFERÊNCIAS}

Allen, A. J., H. Leonard e S. E. Swedo. 1995. "Current knowledge of medications for the treatment of childhood anxiety disorders". Journal of the American Academy of Child E Adolescent Psychiatry 34 (8): 976-986.

https://doi.org/10.1097/00004583-199508000-00007

Alves, M. H. H. 1982. "A Aplicação da Biblioterapia no processo de reintegração social”. Revista Brasileira de Biblioteconomia e Documentação 15 (1-2): 54-61. http://www.brapci.inf.br/_repositorio/2011/08/pdf_09e78c51e2_0018372.pdf

Bahiana, N. D. S. A. 2009. "A utilização da Biblioterapia no ensino superior como apoio para a auto-ajuda: implementação de projeto junto aos educandos em fase de processo monográfico". Revista Digital de Biblioteconomia e Ciência da Informação 7 (1): 65-79. https://doi.org/10.20396/rdbci.v7i1.1975

Barreto, A. A. 1994. "A Questão da informação". Revista São Paulo em Perspectiva 8 (4): 3-8.

Bernardino, M. C. R., A. G. Elliott e M. L. Rolim Neto. 2012. "Biblioterapia com crianças com câncer”. Informação e Informação 17 (3): 198-210. http://www.uel.br/revistas/uel/index.php/informacao/article/view/10992.

Burato, K. R. S., J. A. S. Crippa e S. R. Loureiro. 2009. “Transtorno de ansiedade social e comportamentos de evitação e de segurança: uma revisão sistemática". Estudos de Psicologia 14 (2): 167-174. http://doi.org/10.1590/S1413-294X2009000200010

Caldin, C. F. 2001. "A leitura como função terapêutica: Biblioterapia”. Encontros Bibli: Revista Eletrônica de Biblioteconomia e Ciência da Informação 6 (12): 32-44. https://doi.org/10.5007/1518-2924.2001v6n12p32

Caldin, C. F. 2002. "Biblioterapia para crianças internadas no hospital universitário da UFSC: uma experiência”. Encontros Bibli: Revista Eletrônica de Biblioteconomia e Ciência da Informação 7 (14): 38-54. https://doi.org/10.5007/1518-2924.2002v7n14p38

Caldin, C. F. 2005. "Biblioterapia: atividades de leitura desenvolvidas por acadêmicos do curso de Biblioteconomia da Universidade Federal de Santa Catarina". Biblios 6 (22): 13-25. 
Câmara dos Deputados. 2012. Projeto de Lei no. 4.186, de 11 de julho de 2012. "Dispõe sobre o uso da Biblioterapia nos hospitais públicos, contratados, conveniados e cadastrados do Sistema Unico de Saúde - SUS”. Brasil. https://www.camara.leg.br/proposicoesWeb/fichadetramitacao?idProposi$\mathrm{cao}=551578$

Câmara dos Deputados. 2017. Comissão rejeita uso de Biblioterapia em hospitais do SUS. Brasil, Brasília.

https:/www.camara.leg.br/noticias/514787-comissao-rejeita-uso-de-Biblioterapia-em-hospitais-do-sus/

Campos, R. N., J. A. O. Campos e M. Sanches. 2010. “A evolução histórica dos conceitos de transtorno de humor e transtorno de personalidade: problemas no diagnóstico diferencial". Archives of Clinical Psychiatry 37 (4): 162-166. https://doi.org/10.1590/S0101-60832010000400004

Castro Santana, A. e N. Altamirano Bustamante. 2018. “¿Leer para estar bien?: prácticas actuales y perspectivas sobre la Biblioterapia como estrategia educativo-terapéutica”. Revista Investigación Bibliotecológica 32 (74): 171-192. http://doi.org/10.22201/iibi.24488321xe.2018.74.57918

Ceribelli, C., L. C. Nascimento, S. M. R. Pacífico y R. A. G. Lima. 2009. "A mediação de leitura como recurso de comunicação com crianças hospitalizadas”. Revista Latino-Americana de Enfermagem 17 (1): 81-87. https://doi.org/10.1590/S0104-11692009000100013

Cherpe, S. 2017. A Depressão é uma doença que se trata. Portugal: ADEB.

Costa, M. B. e T. Melnik. 2016. "Efetividade de intervenções psicossociais em transtornos alimentares: um panorama das revisões sistemáticas Cochrane”. Einstein 14 (2): $235-277$. https://doi.org/10.1590/S1679-45082016RW3120

Cunha, M. B. e C. R. O. Cavalcanti. 2008. Dicionário de Biblioteconomia e Arquivologia. Brasília: Briquet de Lemos.

Davison, S. E. 2002. "Principles of managing patients with personality disorder". Advances in Psychiatric Treatment 8 (1): 1-9. https://doi.org/10.1192/apt.8.1.1

Dohnt, H. K. y M. Tiggemann. 2008. "Promoting positive body image in young girls: an evaluation of 'Shapesville”. European Eating Disorders Review 16 (3): 222-233. https://doi.org/10.1002/erv.814

Freud, S. 1980. Luto e melancolia, vol. XIV. Rio de Janeiro: Imago.

Gómez Mujica, K. L. 2017. La Biblioterapia: práctica profesional del bibliotecólogo. Riga (Letônia): EAE Editorial Académica Española.

Jeffcoat, T. e S. C. Hayes. 2012. "A randomized trial of ACT bibliotherapy on the mental health of K-12 teachers and staff". Behaviour Research and Therapy 50 (9): 571-579. https://doi.org/10.1016/j.brat.2012.05.008

Laender, N. R. 2005. “A construção do conceito de superego em Freud”. Reverso: Revista de Psicanálise 27 (52): 63-68. http://pepsic.bvsalud.org/pdf/reverso/v27n52/v27n52a09.pdf

Laplanche, J. y J. B. Pontalis. 1994. Vocabulário da psicanálise. São Paulo: Martins Fontes. Leite, A. C. O. 2009. "Biblioteconomia e Biblioterapia: possibilidades de atuação". Revista de Educação 14 (2): 23-37. http://revista.pgsskroton.com.br/index.php/educ/article/view/1877 
Lucas, E. R. O., C. F. Caldin e P. V. P. Silva. 2006. "Biblioterapia para crianças em idade pré-escolar: estudo de caso". Perspectivas em Ciência da Informação 11 (3): 398-415. http://doi.org/10.1590/S1413-99362006000300008

Mendes, R. M. B. P. 2008. "A literatura e a biblioterapia para crianças com problemas de aprendizagem”. Dissertação (Mestrado). Universidade do Porto, Mestrado em Educação e Bibliotecas. http://repositorio.uportu.pt/handle/11328/150

Michaelis. 1998. Dicionário da língua portuguesa. São Paulo: Melhoramentos.

Mintz, L. B., A. M. Balzer, X. Zhao e H. E. Bush. 2012. "Bibliotherapy for low sexual desire: evidence for effectiveness". Journal of Counseling Psychology 59 (3): 471-78. https://doi.org/10.1037/a0028946

Oliveira, L. R., A. S. Pena, A. R. Justino e A. L. Santos. 2011. "Biblioterapia: uma experiência de ler e contar histórias para pessoas hospitalizadas". Extensio: Revista Eletrônica de Extensão 8 (12): 44-60. https://doi.org/10.5007/1807-0221.2011v8n12p44

Ouaknin, M. A. 1996. Biblioterapia. São Paulo: Loyola.

Pascoal, E. B. e M. R. Ribeiro. 2016. Era uma vez: um guia para a utilização de livros em psicoterapia infantil. Brasília: Instituto Walden4.

Pereira, I. L. 2016. "A importância da Biblioterapia no tratamento da depressão". Trabalho de Conclusão de Curso (Biblioteconomia), Universidade Federal do Estado do Rio de Janeiro, Escola de Biblioteconomia. http://www.unirio.br/unirio/cchs/eb/arquivos/tccs-2016.2/Isabela\%20Lustosa\%20Pereira.pdf

Pereira, M. M. G. 1996. Biblioterapia: proposta de um programa de leitura para portadores de deficiência visual em bibliotecas públicas. João Pessoa: Editora Universitária da UFPB.

Pinto, V. B. A. 2005. "A Biblioterapia como campo de atuação para o bibliotecário". Transinformação 17 (1): 31-43. http://doi.org/10.1590/S0103-37862005000100003

Ratton, A. M. L. 1975. "Biblioterapia". Revista da Escola de Biblioteconomia da UFMG 4 (2): 198-214.

Remor, E. A. 1997. "Contribuições do modelo psicoterapêutico cognitivo na avaliação e tratamento psicológico de uma portadora de HIV”. Psicologia: Reflexão e Crítica 10 (2): 249-261. https://doi.org/10.1590/S0102-79721997000200005

Rezende, J. M. 2009. “Dos quatro humores às quatro bases”, en À Sombra do plátano: crônicas de bistória da medicina, 49-53. São Paulo: Unifesp. http://books.scielo.org/id/8kf92/pdf/rezende-9788561673635-05.pdf

Ribeiro, G. 2006. "Biblioterapia: uma proposta para adolescentes internados em enfermarias de hospitais públicos”. Revista Digital de Biblioteconomia e Ciência da Informação 3 (2): 112-126. https://doi.org/10.20396/rdbci.v3i2.2048

Sadi, H. M. 2011. "Análise dos comportamentos de terapeuta e cliente em um caso de transtorno de personalidade borderline”. Tese (Doutorado em Psicologia Clínica). Universidade de São Paulo, Instituto de Psicologia, São Paulo. http:/www.teses.usp.br/teses/disponiveis/47/47133/tde-04112011-115705/pt-br.php 
Salum, G. A., C. Blaya e G. G. Manfro. 2009. “Transtorno do pânico”. Revista de Psiquiatria do Rio Grande do Sul31 (2): 86-94. http://doi.org/10.1590/S0101-81082009000200002

Santos, A. M. e J. J. Castro. 1998. Stress. Lisboa: Análise Psicológica.

Seitz, E. 2008. "A biblioterapia na humanização da assistência hospitalar do Hospital Universitário da Universidade Federal de Santa Catarina - HU/UFSC”. ETD Educação Temática Digital (Campinas) 9 (2): 145-169. https://doi.org/10.20396/etd.v9i2.824.

Seitz, E. M. 2005. "Biblioterapia: uma experiência com pacientes internados em clinica médica”. ETD - Educação Temática Digital (Campinas) 7 (1): 96-111. https://doi.org/10.20396/etd.v7i1.598

Seitz, E. M. 2006. "Biblioterapia: uma experiência com pacientes internados em clínicas médicas”. Revista ACB 11 (1): 155-170. https://revista.acbsc.org.br/racb/article/view/452/567

Silva, A. B. N. 2013. "Biblioterapia, a cura da alma pela leitura: um estudo acerca de sua aplicação, benefícios e atuação do bibliotecário". Trabalho de Conclusão de Curso (Graduação em Biblioteconomia e Gestão de Unidades de Informação). Universidade Federal do Rio de Janeiro. https://pantheon.ufrj.br/bitstream/11422/215/1/TCC\%20Amanda\%20Barbosa\%20Nogueira\%20da\%20Silva.pdf

Silva, M. E. e G. R. B. Fachin. 2002. "Leitura para portadores de deficiência com necessidades especiais: relato de uma experiência”. Revista ACB 7 (2): 148-156. https://revista.acbsc.org.br/racb/article/view/392/483

Souza, T. R. e A. L. T. Lacerda. 2013. "Depressão ao longo da história", en Depressão teoria e clínica, organizado por J. Quevedo e A. G. Silva, 17-28. Porto Alegre: ARTEMED. https://www.larpsi.com.br/media/mconnect_uploadfiles/c/a/cap_01_72_.pdf

Valência, M. C. P. e M. C. Magalhães. 2015. "Biblioterapia: síntese das modalidades terapêuticas utilizadas pelo profissional”. Biblos: Revista do Instituto de Ciências Humanas e da Informação 29 (1): 5-27.

https://periodicos.furg.br/biblos/article/view/4585

Para citar este texto:

Gusmão, Alexandre Oliveira de Meira e Elaine Gleice Jerônimo de Souza. 2020. "A Biblioterapia como ferramenta de restabelecimento emocional”. Investigación Bibliotecológica: archivonomía, bibliotecología e información 34 (85): 33-59.

http://dx.doi.org/10.22201/iibi.24488321xe.2020.85.58166 